

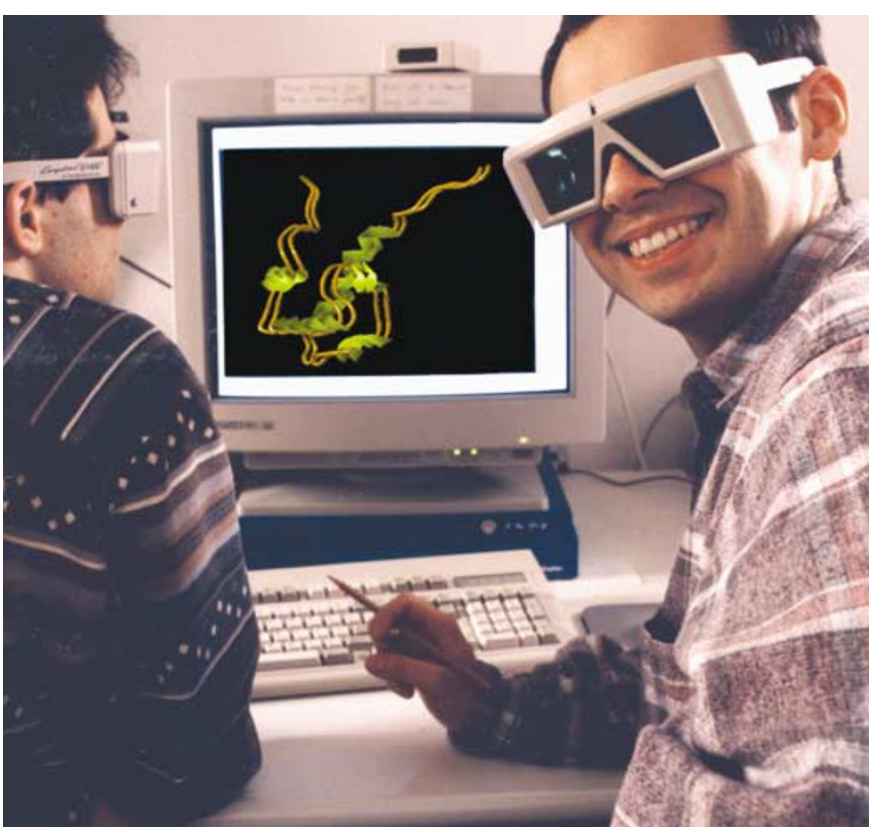

biotech company Syrrx, also in San Diego. "We're trying to assemble an automated pipeline to do highthroughput structural determination with essentially as little manual intervention as possible," Wilson says. Scientists with specialized skills who can anticipate and prevent blocks in the pipeline will also be in high demand.

The biggest technological bottleneck will be producing a high enough percentage of soluble protein. At the moment, even under ideal conditions, only about $20 \%$ of proteins are soluble. And the success ratio goes down considerably as the size of the target protein goes up - especially if the targets include membrane proteins. This is key because, even though they account for about a quarter of all known proteins, membrane proteins make up close to half of the targets that drugs companies are interested in. This means that protein chemists will be in big demand, says Wilson.

\section{PHARMA CAUTIOUS}

Although pharmaceutical companies are eager to exploit structures for drug design, they do not want to spend a lot of money building up infrastructure in the way that the public projects are doing. And they are more cautious about the applied promise of the basic science. Years ago, the conventional wisdom was that structure could be used to develop drugs from the ground up. That has proven to be the exception rather than the rule.

Big companies are now focusing on using existing structures to refine drugs already in the pipeline, says Peter Kim, executive vice-president of research and development at Merck in New Jersey. But the company has slowly increased its activities in structural biology, and this is likely to continue as it brings in more X-ray crystallographers, molecular-modelling experts and protein-expression specialists, he says.

The ability to design drugs from structure will require more basic science - especially about the complex chemical interactions that occur between two molecules. But calculating the energy of such interactions and the binding affinity between molecules is not the kind of work supported by

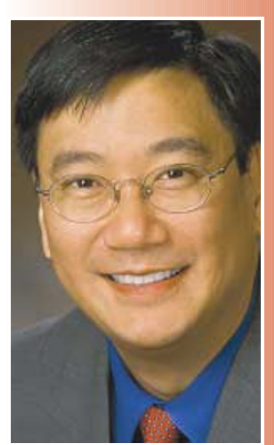

Merck's Peter Kim expects the company to engage in more structural biology.

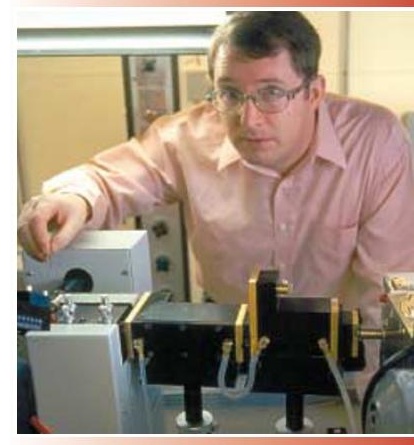

On the up: AstraZeneca has expanded its protein chemistry effort over the past two years.

\section{Automation's crystal ball}

It seems ironic that those behind the projects designed to produce an abundance of new protein structures are hiring relatively few stalwarts of structural biology. Indeed, the largest US structural-genomics initiative is not funding any postdocs, because the project's focus will provide little useful training for fledgling structural biologists.

'Discovery science' has come to structural biology and the employment and funding of scientists in the field promises to be greatly altered. Publicly funded initiatives will initially each produce hundreds of protein structures a year. As they scale up, the number could grow to thousands eventually providing examples of most of the 30,000 or so families of protein folds that occur in nature.

So will this burst of productivity put structural biologists out of work? On the contrary, say leaders in academia and industry. Drugs companies will still need their own structural experts because many of the structures generated by public efforts may be scientifically interesting, but not immediately applicable.

Karl-Heinz Altmann, a chemist at Novartis, says that the high-throughput approach favoured by most public projects may be of little initial relevance to large drugs companies. "We're normally interested in a specific protein," Altmann says. "It's not very helpful to us if we can crystallize protein A when we are interested in protein B."
Some public projects select target proteins using different criteria from industry. They want to cover a wide variety of protein shapes, whereas industry is more interested in proteins that are known to play a role in key pathways. And the commercial sector is also interested in large molecules that are most resistant to a high-throughput approach, such as membrane proteins.

Also, having a structure in the databank from one protein family does not ensure that it will be relevant to developing a drug based on the structure of its relative.

Nigel Darby, vice-president of enabling science and technology (chemistry) at AstraZeneca in Mölndal, Sweden, adds that drugs companies are often more interested in the structures of proteins with different compounds bound to them than in the structures of the proteins alone.

Ian Wilson, director of the Joint Center for Structural Genomics at the Scripps Research Institute in La Jolla, California, agrees that the approaches taken by public and private initiatives are different. But he believes that the sheer quantity of structures will bridge any gaps. "What is going to get transferred to the community is an enormous number of protein structures for which there is no biology," he says. And that will create a lot of exciting opportunities for molecular biologists, in both academia and industry. P.S 
pharmaceuticals - it is far too basic, Kim says. "I would love to see more funding for it."

Kim, like Wilson, sees the more immediate need for applied biochemists. The people most in demand, he says, are those who are adept at protein expression.

"What one has to have in every drug-discovery programme is properly folded, pure, wellcharacterized proteins," Kim says.

Protein wizards are in short supply, agrees Nigel Darby, vice-president of enabling science and technology (chemistry) at AstraZeneca in Mölndal, Sweden. He says that a good protein chemist's abilities should extend beyond just producing proteins.

"Protein engineering to modify the protein is often required to increase the chances of crystallization or to generate good NMR spectra," he says.

AstraZeneca has rapidly built up its structural chemistry team - it has recruited 35 people to its structural biology/protein chemistry effort in the past two years. Recruits have included X-ray crystallographers, NMR experts and molecular biologists who specialize in structure. Perhaps the biggest growth area is in computational chemistry - people who can use both structural and chemical data and apply them to drug design. These sorts of individuals belong to a growing pool of hybrids who are attractive to industry. "People need multiple skill sets — or at least an ability and willingness to acquire new skills," Darby says.

\section{BIOTECH NICHE}

Chemical skills are also in demand in biotech companies that are basing some of their business plans on structural biology, says Raymond Salemme, founder, president and chief scientific officer of 3-Dimensional Pharmaceuticals (3DP) in Exton, Pennsylvania. Salemme believes that mixing combinatorial chemistry and structural biology will produce better drugs.

But his company's biggest need is for biophysicists. The drug-screening strategy at 3DP involves measuring the binding of biological cofactors to genomic targets. Once the affinity has been determined, biologists can unravel a protein's function based on what binds to it. That information, in turn, can be applied to refining the protein-chemistry techniques necessary to crystallize the protein.

Structural GenomiX in San Diego, on the other hand, is setting itself up as a mini version of the US structural-genomics initiative. It is building its own synchrotron beamline, used to help elucidate a protein's shape, at Argonne National Laboratory. Many labs and companies must wait in line for beam time,

\section{An odd road to structural biology}

Stephen Burley of Rockefeller University, New York, and leader of one of the US structuralgenomics initiative's seven centres, could not have picked a more twisted career path to his current position. As an undergraduate "I was a computer nerd", he says. Although interested in the quantitative sciences, biology caught his eye, so he did a doctorate at
Oxford in molecular

biophysics.

Needing more

training in biology, he went to Harvard Medical School. "I loved patient care," he says. But he also loved research. $\mathrm{He}$ soon realized that he had to decide between balancing research and care or doing research full time. He postponed the decision by doing a research residency at Harvard-affiliated Brigham and Women's Hospital. The stint allowed him to split the difference of his interests - six months in the lab, six months on the wards. "I discovered I couldn't do both," Burley says.

Solving the structure of the TATA box protein (see Nature 360, 40-46; 1992) put him on the road to full-time structural biologist. In retrospect, his path to leadership in structural genomics seems obvious. so having its own will help the company skip the queue. At the moment, Structural GenomiX is seeking technical people to assist in automation. Once the beamline is complete, the company will start recruiting structural biologists.

British company Astex is taking, if anything, the opposite approach. It is choosing target proteins that it thinks will be attractive to industry and focusing on those, says Harren Jhoti, chief scientific officer and cofounder of the Cambridge-based company. Its recruitment strategy matches its scientific and business schemes.

And once targets have been selected, the company will turn to third-party technology providers, rather than try to do all the automation itself. Although eager to benefit from the structural biology industrial revolution, Astex, like many larger companies, is happy to let someone else build the factory. Paul Smaglik is editor of Naturejobs.

Web links

NIGMS structural-genomics initiative

http://www.nigms.nih.gov/funding/psi.html

Joint Center for Structural Genomics

http://www.jcsg.org/home.html

Human Proteome Organisation http://www.hupo.org 